\title{
Emerging Transit Technology: Implementing an Urban Gondola System over Al Corniche, Doha, Qatar - A Cost Estimation Study
}

\author{
Shahram Tahmasseby \\ stahmasseby@qu.edu.qa \\ Qatar Transportation and Traffic Safety Center, Qatar University, Doha, Qatar
}

\begin{abstract}
Urban gondolas are a type of driverless transit vehicles, which are increasingly drawing the attention as a viable mass transit alternative in urban environments and touristic areas. The system is distinctive with high reliability of travel time, because it operates on their own right of. Urban gondolas are also identified with environmental benefits resulting from their low emission, energy use, and noise pollution. They have widely been implemented in touristic areas, mountains and in areas with diverse topography types. The objective of this study is a first step assessment of the potential economic viability of implementing an urban Gondola linking East Mound Skyline View to the promenade side along Al Dafna Park in Westbay Doha, Qatar. The focus of this study is on introducing an appropriate technology plus estimating its associated cost components of implementing such system in Qatar. The (Monocable) urban gondola technology will be investigated in terms of applicability and furthermore, their associated cost components including the capital costs such as infrastructure civil works, as well as operating and maintenance costs (O\&M) will be estimated based on the existing benchmarks and similar practices from around the globe. The result of this study could be a basis for an in-depth Cost-Benefit Analysis of implementing emerging transit technologies (e.g. urban gondola) in the State of Qatar.
\end{abstract}

Keywords: Urban gondola; Cost estimation; Emerging transportation; Operation and maintenance costs

\section{INTRODUCTION AND BACKGROUND}

A gondola lift, also called a cable car, is a type of aerial lift which is held and driven by cables from overhead. The cable is in the form of a circular steel rope that is strung between two ending points and might also passes over in-between auxiliary towers. The cable is propelled by a bull wheel in a terminal, which is powered up by a diesel-powered or electric-powered engine. Basically, gondola systems are frequently seen as a nonstop/uninterrupted transportation system given their haul rope continual movement and circulating around two terminating points function. The associated capital and operating costs, functionality and capacity of a gondola system may vary based on the combination of cables used for support and/or haulage and the type of grip (detachable grip vs. fixed grip).

In the past, gondolas were conventionally designed and implemented in the ski resorts having mountainous terrain; however, recently they are being designed and used in urbanized areas and considered as a public transportation mode e.g. Metrocable (Medellín), Portland Aerial Tram, Metrocable (Caracas), Cable Aéreo (Manizales) and 
Constantine (Algeria) (SJC Alliance Consulting Services- Creative Urban Projects CUP, 2019).

The Metrocable systems in Medellin and Caracas are fully integrated with the public transit network. This enables passengers to seamlessly transfer to the local metro lines. The City of London in the UK, built Emirates Air Line (cable car) for the 2012 Summer Olympics which facilitates travel from Emirates Greenwich Peninsula terminal to Emirates Royal Docks terminal in six minutes. Alshalalfah and Shalaby (2011) examined the potentiality and feasibility of an urban gondola system to address some of Mecca's transportation issues such as mobility, accessibility, safety and security, equity, sustainability and the economy. Their study demonstrated that depending on the chosen corridor and applied technology, the benefit over cost ratio (BCR) ranges from 1.04 to 4.26. The indirect costs remunerations in that study stemmed from travel time savings, vehicle operating cost savings, GHG (greenhouse gas emission) savings, as well as air pollution savings (i.e. nitrogen oxides, volatile organic compounds, sulphur oxides, $\mathrm{PM}_{10}$, and carbon monoxide).

In 2018, TransLink, the public transit company in Vancouver- British Columbia, examined the feasibility of building a gondola to connect SkyTrain (Production Way University Station) with Burnaby Mountain, including the main campus of Simon Fraser University (Ch2M Hill Report 2018). The introduction of the abovementioned gondola would result in the elimination of the bus service from Production Way-University Station to Burnaby Mountain and its replacement by a gondola service, which would yield to some bus capital and operating cost savings to offset. $\mathrm{CH} 2 \mathrm{M}$ estimated that TransLink will be able to recover $\$ 34.5$ million in capital costs as well as a 25 -year reduction of $\$ 89.3$ million in bus operations. Furthermore, the operating cost of the gondola was estimated to hover around $\$ 54.2$ million. Including the gondola capital cost, the total cost was approximated $\$ 123.4$ million. Consequently, by dividing $\$ 225.3$ million as the estimated total benefits of implementing the gondola over the indicated capital and operating costs for a 25 year period of operation, a BCR of 1.8 was calculated which showed that the overall benefits of the BMGT project would outweigh its costs.

\section{GONDOLA SYSTEMS CONSTITUENTS}

Nearly all gondola systems are constituted by similar components, despite differences in the applied technique. Basically, gondola systems are constituted from the following fundamental elements:

- carriers (cabins);

- terminals;

- towers;

- ropes; and

- an emergency arrangement for the safe evacuation.

In general, gondolas are considered as a reliable and cost-effective system, thanks to their system energy efficiency. They offer a safe and efficient transport system particularly in hilly terrains. Furthermore, implementing gondola systems as a public transport mode may cut GHG emission and reduce air pollution in urbanised areas. Nonetheless, they might be vulnerable due to the risk of power outages. In case of a hazard e.g. power outage, evacuation is challenging. However, Medellín Metro is ameliorating this problem 
by providing a communication system in every vehicle should an emergency occur ( $S J C$ Alliance Consulting Services- Gondola Project Medellin).

Currently, gondolas that have been used as a mass transit mode in urban areas use one of the following three technologies:

- Monocable Detachable Gondolas (MDG);

- Bicable Detachable Gondolas (BDG); and

- Tricable Detachable Gondolas (TDG, or 3S).

The aforementioned technologies are different in terms of speed, capacity, structure, and operation and consequently capital and O\&M costs. In terms of mobility, the applicable capacity of a MDG system hovers around 2,000 to 3,000 pax per hour per direction (pphpd). This figure increases to 4,000 pphpd for BDG and can even reach up to even the nominal capacity of above 5000 pphpd for $3 \mathrm{~S}$ gondola systems. Practically, reaching to 4000 pphpd is feasible for gondola. For the case of Burnaby, the gondola supplier suggested the aforementioned capacity by presuming cabins travelling with gaps of less than 1 minute and taking 6 to 7 minutes to complete a trip and having capacity of 33 passengers per cabin (Ch2M Hill report 2018). Obviously, the capital cost of implementing a $3 \mathrm{~S}$ gondola system will be a way higher than that of other systems e.g. MDG.

In this case study the MDG system is considered as an appropriate system based on the size of demand catchment area and thus the anticipated patronage. Generally, MDG cabins hold 8 passengers while some systems allowing as few as 4 or as many as 15 . As indicated before, this normally amounts to around 2,000-3,000 people per hour per direction, if the cabin cars with the highest capacity are adopted. As indicated before, Monocable Detachable Gondolas (MDG) are likely the most common aerial urban transit system as their low cost has made them an attractive complementation to public transit systems particularly in the developing countries. MDG systems have been installed in South American cities in Colombia, Venezuela, Brazil, as well in Africa Europe and Asia such as in Algeria, England and Singapore respectively. Table 1 summarizes service and technology characteristics of MDG gondola which is suitable for the case study.

Table 1: MDG System and Technology Characteristics

\begin{tabular}{|c|c|}
\hline System characteristics & Description \\
\hline Cabin capacity & 15 passengers \\
\hline Service line headway & 15 seconds \\
\hline Service line capacity & Upgradable to 3,600 persons $/ \mathrm{hr}$ \\
\hline Maximum line speed & $6 \mathrm{~m} / \mathrm{s}(21.6 \mathrm{~km} . \mathrm{hr})$ \\
\hline Max Distance between Towers & 900 meters \\
\hline $\begin{array}{c}\text { Dwell time at terminal [per } \\
\text { terminal] }\end{array}$ & 122 seconds \\
\hline $\begin{array}{c}\text { Dwell time at intermediary sta- } \\
\text { tions (per station) }\end{array}$ & 42 seconds \\
\hline
\end{tabular}




\section{CASE STUDY- MONOCABLE DETACHABLE GONDOLA (MDG) OVER AL CORNICHE}

In this study the proposed gondola system constitutes a single line which connects East Mound Skyline View to the promenade side along Al Dafna Park in Westbay Doha, Qatar, see Exhibit (1) for the proposed line alignment. The length of the line is approximately $2.15 \mathrm{Kms}$ and there will be no intermediary stations along the proposed line.

\subsection{Gondola Capital Cost}

The cost estimates indicated in this section have been obtained from the existing major vendors of Arial Ropeway Transit technologies in the world [Doppelmayr/ Garaventa Group and Leitner Ropeways]. Hence, the quoted cost estimates alterations are marginal. Generally, the cost components associated with the investment in Gondola can be outlined as follows:

The cost estimates indicated in this section have been obtained from the existing major vendors of Arial Ropeway Transit technologies in the world [Doppelmayr/ Garaventa Group and Leitner Ropeways]. Hence, the quoted cost estimates alterations are marginal. Generally, the cost components associated with the investment in Gondola can be outlined as follows:

- Propulsion, which comprises a major part of the gondola infrastructure costs;

- Infrastructure equipment: include costs of cabins, towers, cables and any other related infrastructure costs such as the cabin carriage, power supply and telecommunication systems;

- Terminal/ in-between stations, the essential costs allocated to build gondolas' basic infrastructure, architectural and civil works. This includes construction of a gondola terminating and/in-between stations comprise terminal/ intermediary stations capital costs;

- $\quad$ Required civil works i.e. foundations; piling; cupping; and soil tests.

- Reserved generator; The cost of a backup generator comprises a negligible percentage of the total capital cost of a gondola system

- Duty on equipment which represents the expenses of the duty on the electromechanical components of the propulsion system at terminals and intermediary stations.

- Contingency plan: based on existing experiences in Gondola systems, the contingency expense is presumed to be $20 \%$ of the entire capital cost; and

- Land acquisition, if applicable. In this study the cost of land acquisition was not taken into account

Table (2) outlines the investment and capital costs for the proposed Al Corniche gondola line for the MDG Technology. 


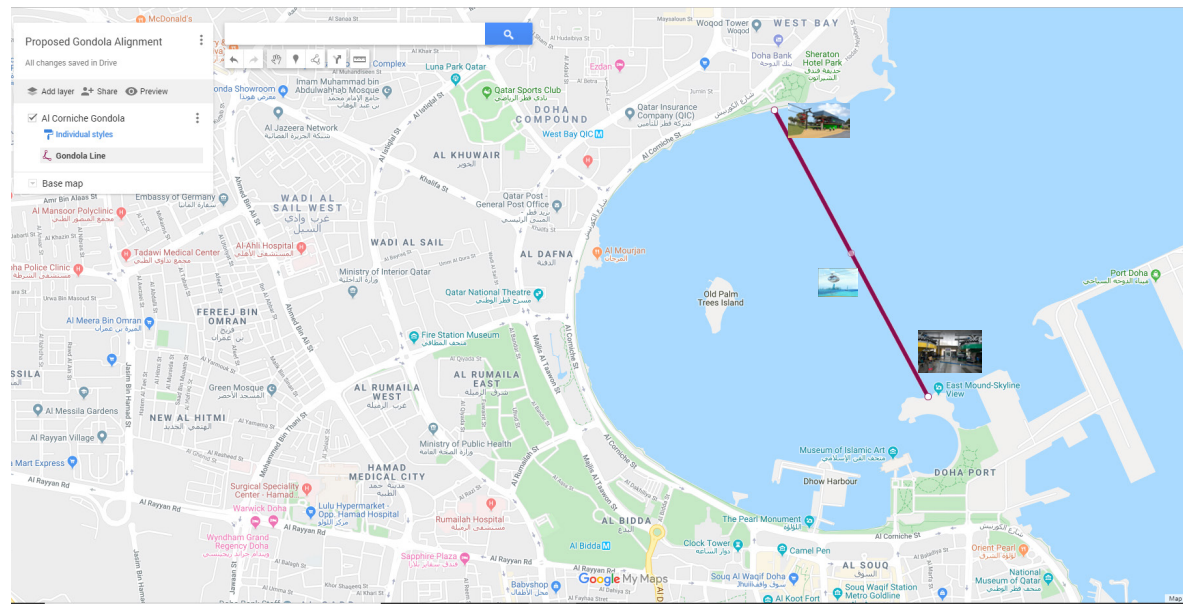

Figure 1: Proposed Gondola Alignment over Al Corniche, Doha, Qatar

Table 2: Capital Cost Components Estimation for the Proposed Gondola Line

\begin{tabular}{|c|c|c|}
\hline Capital Cost Component & Remarks & $\begin{array}{c}\text { Cost in } \\
\text { QR (M) }\end{array}$ \\
\hline Propulsion at terminals & Drive (terminal) + Return (terminal) & 0.5 \\
\hline $\begin{array}{c}\text { Propulsion at Intermediate } \\
\text { Stations }\end{array}$ & Not applicable & 5.6 \\
\hline Terminals Capital costs & Skyline View Terminal + Al Dafna \\
Terminal & Not applicable & 0.0 \\
\hline Intermediate stations Capital & QR9.4 M per Km & 20.7 \\
\hline Infrastructure (lines) & Approximately QR 2.8 M per km & 0.2 \\
\hline Infrastructure civil works & $\begin{array}{c}\text { Estimated as 10\% of the Electro- } \\
\text { Mechanical parts associated costs }\end{array}$ & 2.9 \\
\hline Backup Generator & One fifth of the total capital costs (20\%) & 8.7 \\
\hline Duty on equipment & $\mathbf{5 2 . 2}$ \\
\hline Contingency & Total Capital Costs & \\
\hline
\end{tabular}

\subsection{Operating and Maintenance $(\mathrm{O} \& \mathrm{M})$ Costs of the Proposed Gondola}

The $\mathrm{O} \& \mathrm{M}$ cost for Gondola systems consists of the following components (Tupper 2009, Alshalalfah and Shalaby, 2011):

- Energy consumption cost which represents the associated costs of the energy (often electric power or diesel fuel) and water consumption;

- Manpower costs which are generally insignificant due to the automated system as presumed two (2) personnel (incl. a mechanic) are allocated to each station during its 18 hours operation;

- Recurrent maintenance and service costs: the maintenance costs generally range from QR 250 to QR 550 per hour of operations based on 14 hours of operation (Warren, 2011);

- Applicable insurance costs: relatively significant because of the uniqueness of the system; and

- Capital reserve fund costs which is the accrual of a capital reserve fund for future capital expenditures in order to rehabilitate the entire system during its lifetime period. 
The total operating and maintenance cost of each Gondola option (annually) is outlined in table (3).

Table 3: O \& M Cost Components Estimation for the Proposed Gondola Line per Year

\begin{tabular}{|c|c|c|}
\hline $\begin{array}{c}\text { O \& M Cost } \\
\text { Component per } \\
\text { Annum }\end{array}$ & Remarks & Cost in QR (M) \\
\hline Energy consumption & Figure is based on similar case studies & 1.0 \\
\hline Personnel wage & Assumed QR 140 per hour for mechanics & 3.6 \\
\hline Maintenance cost & Assumed QR 420 per hour & 2.7 \\
\hline Insurance cost & $\begin{array}{c}\text { The figure was derived from a Canadian Gondola } \\
\text { case study in British Columbia }\end{array}$ & 0.6 \\
\hline Capital reserve fund & $\begin{array}{c}\text { It's presumed over a 25-year period QR11M-16M } \\
\text { will be required for the overhaul or improvements of } \\
\text { major gondola components }\end{array}$ & $0.5^{1}$ \\
\hline & Total O\&M Costs per Annum & $\mathbf{8 . 4}$ \\
\hline
\end{tabular}

\section{WAY FORWARD}

Following the calculation of the capital, operation and maintenance costs, the next step will be the estimation of the benefits of gondola, which will make conducting a cost -benefit analysis and concluding a comprehensive assessment of viability of implementing such system in Doha, Qatar possible. The project economic efficiency can be examined from the social welfare perspective. The NPV (net present value), and IRR (internal rate of return) are two appropriate economic indicators when it comes to cost-benefit analysis. Calculating the following ex-ante economic benefits is necessary in this regard:

- Estimation of the system patronage: ridership needs to be estimated by applying a methodology based on the transit catchment area concept, and choice behaviour modeling. Conducting a stated preference (SP) survey could be considered as a necessary step in this context to measure the potential riders' tendency and willingness to ride gondola. The estimation of demand at the ex-ante stage should be realistic and thus commensurate with the gondola system capacity (derived from the service frequency, applied technology and the cabin car capacity). As the travel demand for public transport projects is often estimated for a project's lifetime to enable the transport authorities to examine the project economic viability, a thirtyyear lifetime window can be deemed for gondola in this case study as a customary figure for gondola technology.

- The estimation of gondola patronage could lead to measure Travel Time Savings and perceived Travel Time Reliability for car and bus users at an aggregate level. It is noteworthy to mention that apart from leisure, the aforementioned metrics are considered as important advantages of riding a gondola from passengers'

1 To build up QR 17 Million over 25 years and considering 2\% interest rate, the capital reserve fund is estimated QR $521 \mathrm{~K}$ per annum. It was presumed that no capital expenditures would be required for the first 8 to 10 years, ensuring that $\mathrm{QR} 5.6 \mathrm{M}$ to $\mathrm{QR} 7.0 \mathrm{M}$ would be accumulated by that time to cover such an expense. 
perspective. Gondola riders actually benefit from a convenient service line offering very short waiting times, reliable as well as direct service connecting the two sides of $\mathrm{Al}$ Corniche without requiring any additional boarding, stopping and alighting. Furthermore, it is never impacted by traffic congestion, traffic signals, road constructions, detours, etc.

- Car operating cost savings given the impacts of gondola on the road network, and

- Environmental benefits, in terms of reduced air pollution emissions.

Finally, the qualitative impacts of factors other than those indicated, which may also be difficult to measure, should be included in project assessment and performance benchmarking. An overall evaluation of Gondola viability over Al Corniche and its surrounding areas needs to be accounted for by qualitatively assessing the following factors:

- Economic efficiency;

- Capacity;

- Convenience and accessibility;

- Operating profitability;

- Sustainability and GHG emissions reduction;

- Visual intrusion impacts;

- Safety, reliability and weather issues.

\section{CONCLUSION}

In this study, the associated costs i.e. capital, operating and maintenance costs of a Monocable Detachable Gondola (MDG) technology connecting two sides of Al Corniche in Doha, the State of Qatar was investigated. The cost estimation presented in this study, in fact was the first step toward a comprehensive feasibility assessment of implementing an urban gondola, as an emerging transit technology, at the ex-ante stage in the country. It was emphasized that the Cost-Benefit Analysis (CBA) is a relevant method to estimate economic metrics such as Benefit over Cost ratio which help the stakeholders and decision makers in justifying the project viability. Furthermore, it was recommended that the project has to be examined qualitatively by incorporating indirect measures such as sustainability, visual intrusion, convenience and accessibility indices.

\section{REFERENCES}

Alshalalfah, B., Shalaby, A. \& Othman. F. (2011). Aerial ropeway transit-Exploring its potential for Makkah. Center of Research Excellence in Hajj and Morah, University of Toronto.

CH2M HILL Canada Limited (2018). Burnaby Mountain Gondola Transit - Feasibility Study. Prepared for TransLink.

SJC Alliance Consulting Services (2019). Creative Urban Projects CUP. Accessible at: www. gondolaproject.com

SJC Alliance Consulting Services (2019). Gondola Project Medellin. Accessible at: http:// gondolaproject.com/medellin/

Tupper. B. (2009). Proposed Burnaby Mountain Gondola Transit Project, UniverCity on Burnaby 
Mountain.

Warren K. (2011). Keeping the gondola running TMVOA, Mountain Village fund and operate the gondola. Accessible at: https://www.telluridenews.com/news/article_b8ec1825-c8bd-57ea9a95-10330e9a5803.html

Cite this article as: Tahmasseby S., "Emerging Transit Technology: Implementing an Urban Gondola System over Al Corniche, Doha, Qatar - A Cost Estimation Study", International Conference on Civil Infrastructure and Construction (CIC 2020), Doha, Qatar, 2-5 February 2020,DOI: https://doi. org/10.29117/cic.2020.0046 